\title{
Interface Double-Exchange Ferromagnetism in the Mn-Zn-O System: New Class of Biphase Magnetism
}

\author{
M. A. García, ${ }^{1,2}$ M. L. Ruiz-González, ${ }^{3}$ A. Quesada,,${ }^{1,2}$ J. L. Costa-Krämer, ${ }^{4}$ J. F. Fernández, ${ }^{5}$ S. J. Khatib, ${ }^{6}$ A. Wennberg, ${ }^{4}$ \\ A. C. Caballero, ${ }^{5}$ M. S. Martín-González, ${ }^{4}$ M. Villegas, ${ }^{5}$ F. Briones, ${ }^{4}$ J. M. González-Calbet, ${ }^{1,3}$ and A. Hernando ${ }^{1,2, *}$ \\ ${ }^{1}$ Instituto de Magnetismo Aplicado (RENFE-UCM-CSIC), P.O. Box 155, 28230 Las Rozas, Madrid, Spain \\ ${ }^{2}$ Departamento de Física de Materiales, UCM, 28040 Madrid, Spain \\ ${ }^{3}$ Departamento de Química Inorgánica I, UCM, 28040 Madrid, Spain \\ ${ }^{4}$ Instituto de Microelectrónica de Madrid, CNM-CSIC, Isaac Newton 8 PTM, 28760 Tres Cantos, Madrid, Spain \\ ${ }^{5}$ Instituto de Cerámica y Vidrio, CSIC, Cantoblanco, 28049 Madrid, Spain \\ ${ }^{6}$ Instituto de Catálisis y Petroleoquímica, CSIC, Cantoblanco, 28049 Madrid, Spain
}

(Received 9 February 2005; published 3 June 2005)

\begin{abstract}
In this Letter, we experimentally show that the room temperature ferromagnetism in the $\mathrm{Mn}-\mathrm{Zn}-\mathrm{O}$ system recently observed is associated with the coexistence of $\mathrm{Mn}^{3+}$ and $\mathrm{Mn}^{4+}$ via a double-exchange mechanism. The presence of the $\mathrm{ZnO}$ around $\mathrm{MnO}_{2}$ modifies the kinetics of $\mathrm{MnO}_{2} \rightarrow \mathrm{Mn}_{2} \mathrm{O}_{3}$ reduction and favors the coexistence of both $\mathrm{Mn}$ oxidation states. The ferromagnetic phase is associated with the interface formed at the $\mathrm{Zn}$ diffusion front into $\mathrm{Mn}$ oxide, corroborated by preparing thin film multilayers that exhibit saturation magnetization 2 orders of magnitude higher than bulk samples.
\end{abstract}

DOI: 10.1103/PhysRevLett.94.217206

PACS numbers: 75.50.Pp, 75.70.Cn, 82.33.Pt

Prompted by the need to understand the unusual magnetic properties recently observed in the Mn-Zn-O system, considerable work has been carried out. The first observation of room temperature (RT) ferromagnetism (FM) was reported by Sharma et al. [1] in low Mn content $\left(10 \% \mathrm{MnO}_{2}-90 \% \mathrm{ZnO}\right.$ and $\left.2 \% \mathrm{MnO}_{2}-98 \% \mathrm{ZnO}\right)$ pellets annealed at $500{ }^{\circ} \mathrm{C}$. The ferromagnetic behavior was first explained in terms of the formation of $\mathrm{Mn}$-doped $\mathrm{ZnO}$, which was previously predicted to be a dilute magnetic semiconductor with a Curie temperature above $300 \mathrm{~K}$ [2]. However, the origin of the reported ferromagnetic behavior is still a matter of controversy. Kundaliya et al. [3], based on thermogravimetric analysis (TGA) experiments, suggested an oxygen-vacancy $\mathrm{Mn}_{2-x} \mathrm{Zn}_{x} \mathrm{O}_{3-\delta}$ phase as responsible for the observed RT FM. Moreover, recent studies evidence the absence of magnetic order in Mn-doped $\mathrm{ZnO}$ down to $2 \mathrm{~K}$ [4,5]. In a recent paper [6], RT FM was confirmed in samples prepared following Sharma et al. method, although differences concerning the structural characterization have been found. Actually, only a weak $\mathrm{Zn}$ diffusion into $\mathrm{MnO}_{2}$ grains is observed, whereas the presence of $\mathrm{Mn}$ into the $\mathrm{ZnO}$ matrix is never detected. In any case, the mechanism responsible for the RT FM has not been elucidated yet. In this sense, the aim of this work is focused on the study of the origin of the RT FM in the $\mathrm{Mn}-\mathrm{Zn}-\mathrm{O}$ system.

$2 \% \mathrm{MnO}_{2}-98 \% \mathrm{ZnO}$ and $10 \% \mathrm{MnO}_{2}-90 \% \mathrm{ZnO}$ pellets were prepared following the method described by Sharma et al. $[1,6]$. Pure $\mathrm{MnO}_{2}$ samples were also studied for comparison purposes. These samples were annealed in air at different temperatures in the range $500{ }^{\circ} \mathrm{C}-800^{\circ} \mathrm{C}$ for $12 \mathrm{~h}$. After annealing at $500^{\circ} \mathrm{C}$, the $\mathrm{ZnO}-\mathrm{MnO}_{2}$ samples exhibit RT ferromagnetic behavior, as previously reported [6].
The x-ray diffraction pattern shown in Fig. 1(a) and corresponding to the $10 \% \mathrm{MnO}_{2}-90 \% \mathrm{ZnO}$ sample can be indexed on the basis of a mixture phase constituted by a majority one $(\mathrm{ZnO})$, one minority, around $5 \%\left(\mathrm{Mn}_{2} \mathrm{O}_{3}\right)$, and traces of $\mathrm{MnO}_{2}$ and $\mathrm{Zn}_{x} \mathrm{Mn}_{3-x} \mathrm{O}_{4}$. This result can be understood taking into account that $\mathrm{MnO}_{2}$ can be partially reduced to $\mathrm{Mn}_{2} \mathrm{O}_{3}$ when treated at $500{ }^{\circ} \mathrm{C}$, the temperature at which a total diffusion of $\mathrm{Zn}$ into $\mathrm{Mn}$ oxide grains is far from being reached. On the other hand, it is well known that $\mathrm{x}$-ray diffraction (XRD) supplies average structural information. This means that if local diffusion of $\mathrm{Mn}$ in $\mathrm{Zn}$ has happened it could not be detected by this technique. In this sense, a transmission electron microscopy study linked with energy-dispersive x-ray spectroscopy (EDS) analysis has been performed to check if any local diffusion has succeeded. This information would be, indeed, very valuable in order to understand the observed magnetic properties. EDS analysis shows the presence of particles exhibiting different composition. The majority ones contain only $\mathrm{Zn}$, while around 5\% involves only Mn. A third type, in a very low ratio, comprising both cations, also appears. Selected area electron diffraction (SAED) patterns of the particles containing $\mathrm{Mn}$ and $\mathrm{Zn}$ separately can be, respectively, indexed on the basis of the $\mathrm{ZnO}$ and $\mathrm{Mn}_{2} \mathrm{O}_{3}$ unit cells, in agreement with the XRD study. On the other hand, particles containing both cations display $\mathrm{Mn} / \mathrm{Zn}$ average ratios between 2.5 and 4 . Moreover, inside each crystal changes in the $\mathrm{Mn} / \mathrm{Zn}$ ratio are apparent. The SAED and the high resolution electron microscopy (HREM) study suggest that in each region containing $\mathrm{Mn}$ and $\mathrm{Zn}$ a spinel-like structure is stabilized. As a representative example, for a $\mathrm{Mn} / \mathrm{Zn}=2.5$ ratio, a HREM image and its corresponding fast Fourier transform (FFT) along the [131] zone axis are displayed in Fig. 1(b). 

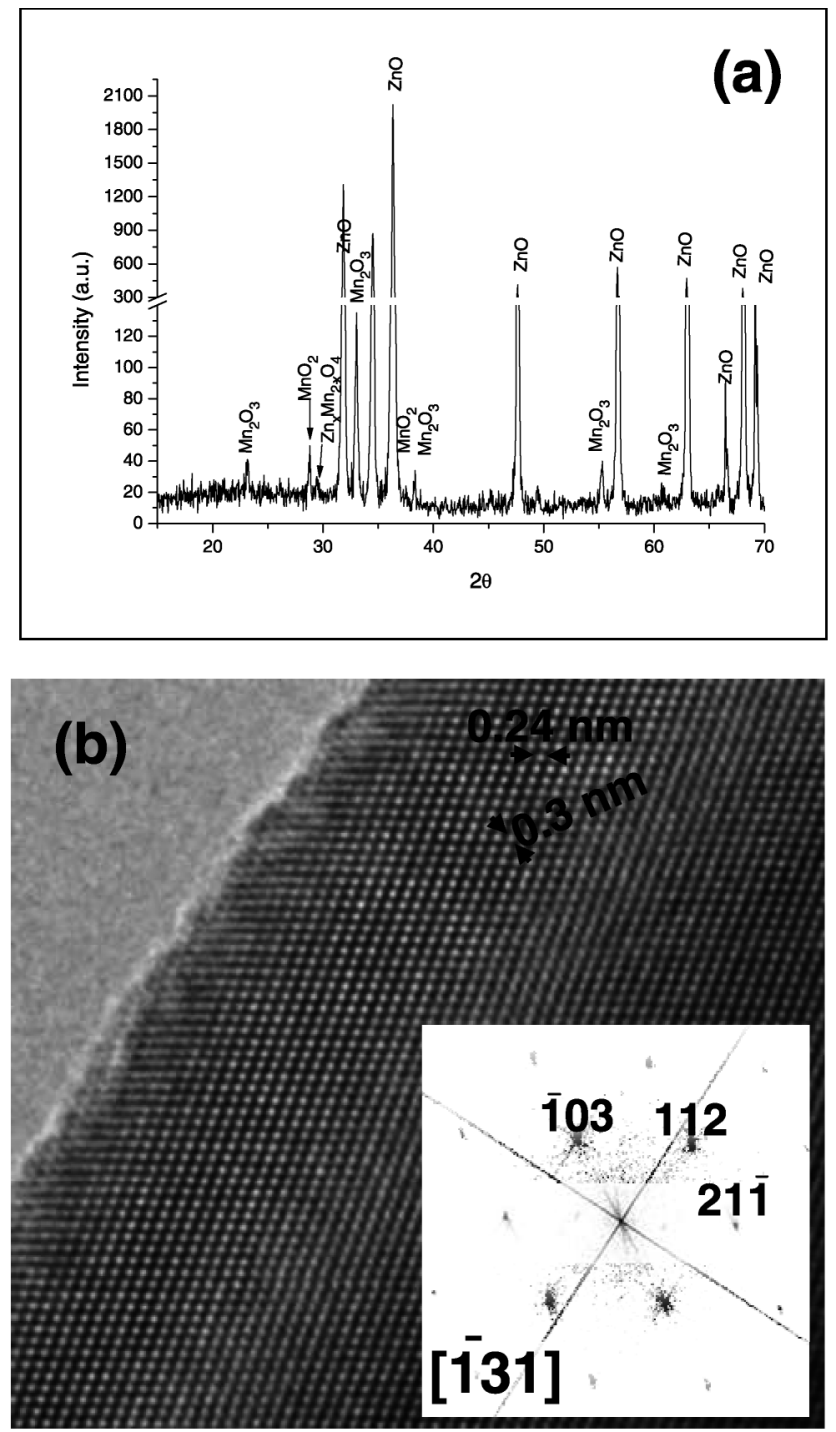

FIG. 1. (a) XRD pattern corresponding to the $10 \% \mathrm{MnO}_{2}-90 \% \mathrm{ZnO}$ sample. Peaks can be indexed and labeled on the basis of the mixture of $\mathrm{ZnO}, \mathrm{Mn}_{2} \mathrm{O}_{3}, \mathrm{MnO}_{2}$, and $\mathrm{Zn}_{x} \mathrm{Mn}_{3-x} \mathrm{O}_{4}$. (b) HREM image of a crystal containing both $\mathrm{Zn}$ and $\mathrm{Mn}$ cations along the [131] zone axis. Periodicities are in agreement with a spinel cell. Inset shows the corresponding FFT.

Changes in the microstructure were not found on particles having different $\mathrm{Mn} / \mathrm{Zn}$ ratios, suggesting that a solid solution $\mathrm{Zn}_{x} \mathrm{Mn}_{3-x} \mathrm{O}_{4}(0 \leq x \leq 1)$ can be formed when $\mathrm{MnO}_{2}$ and $\mathrm{ZnO}$ are heated up together. It is remarkable that the $\mathrm{Zn}$ content is never found to be $x \geq 1$; i.e., the spinel phase is always $\mathrm{Mn}$ rich. On the other hand, it is clear that the proportion of this phase is very low, in agreement with $\mathrm{x}$-ray diffraction information. Evidence of $\mathrm{Mn}$-doped $\mathrm{ZnO}$ was not detected.

Increasing the annealing temperature above $600^{\circ} \mathrm{C}$ gives rise to a decrease of the FM signal at room temperature that completely disappears after annealing at $800{ }^{\circ} \mathrm{C}$ [Fig. 2(a)], in agreement with previous studies [1]. The XRD patterns of the annealed samples displayed in
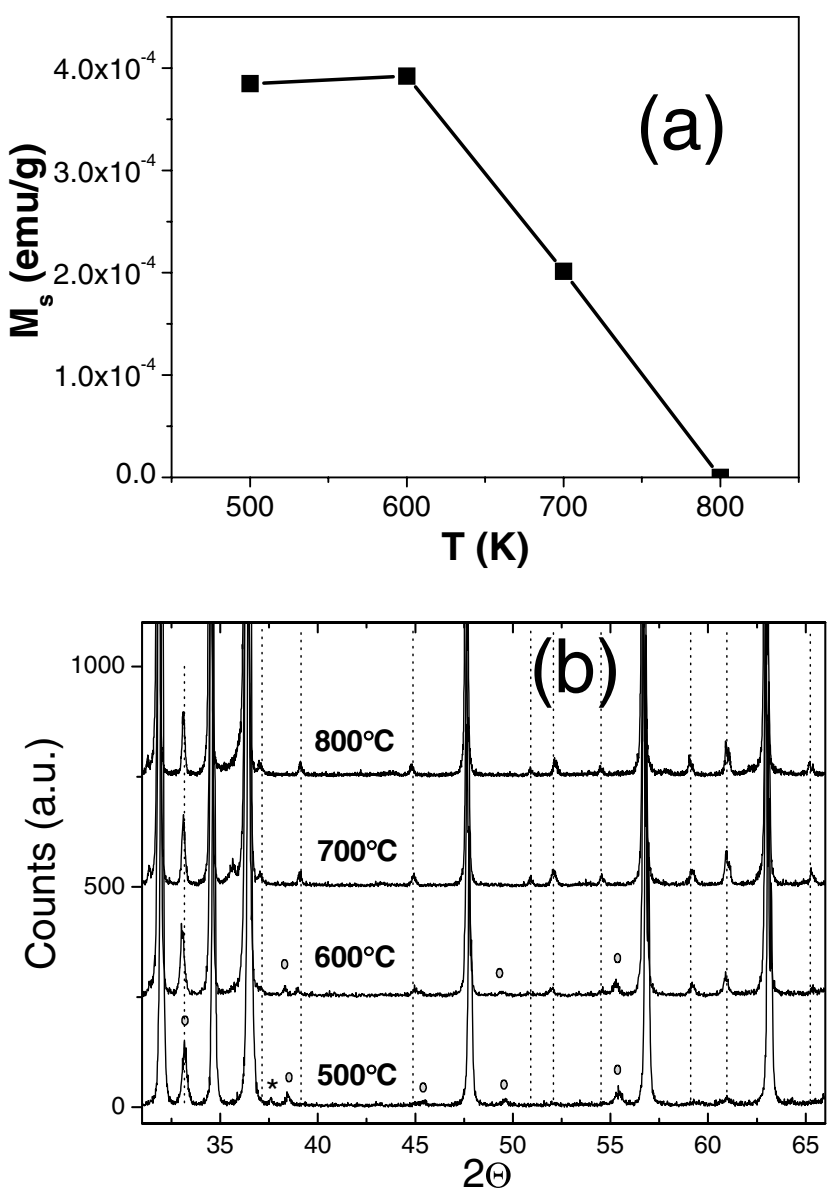

FIG. 2. Evolution of (a) $\mathrm{M}_{\mathrm{s}}$ and (b) XRD patterns with the annealing temperature from the $10 \% \mathrm{MnO}_{2}-90 \% \mathrm{ZnO}$ sample. Dashed lines, circles, and asterisk represent the main peaks from $\mathrm{Zn}_{x} \mathrm{Mn}_{3-x} \mathrm{O}_{4}, \mathrm{Mn}_{2} \mathrm{O}_{3}$, and $\mathrm{MnO}_{2}$, respectively.

Fig. 2(b) indicate structural changes. Above $500^{\circ} \mathrm{C}$, the very weak signal corresponding to $\mathrm{MnO}_{2}$ disappears while the $\mathrm{Mn}_{2} \mathrm{O}_{3}$ peak intensity starts decreasing. In addition, new peaks characteristic of a spinel-like phase, $\mathrm{Zn}_{x} \mathrm{Mn}_{3-x} \mathrm{O}_{4}$, appear and their intensities increase as the temperature is enhanced. The HREM study of the sample treated at $800^{\circ} \mathrm{C}$ confirms a $\mathrm{Zn}$ rich spinel structure, suggesting that heating has allowed further diffusion of $\mathrm{Zn}$. The simultaneous increase of the $\mathrm{Zn}_{x} \mathrm{Mn}_{3-x} \mathrm{O}_{4}$ phase and decrease of the ferromagnetic signal suggests that this phase is not responsible for the RT FM. Although there is some controversy about the magnetic properties of this spinel, it is well known that it exhibits paramagnetic behavior at RT [7]. For a further understanding, several samples in the $\mathrm{Zn}_{x} \mathrm{Mn}_{3-x} \mathrm{O}_{4}$ system have been prepared and characterized. FM at RT was never observed in this solid solution.

Since no manganese oxides are ferromagnetic at room temperature, the observed FM must be related to the reaction of $\mathrm{MnO}_{2}$ with $\mathrm{ZnO}$ prior to the final formation of the $\mathrm{Zn}_{x} \mathrm{Mn}_{3-x} \mathrm{O}_{4}$ spinel. The kinetics of $\mathrm{MnO}_{2}$ reduction is 

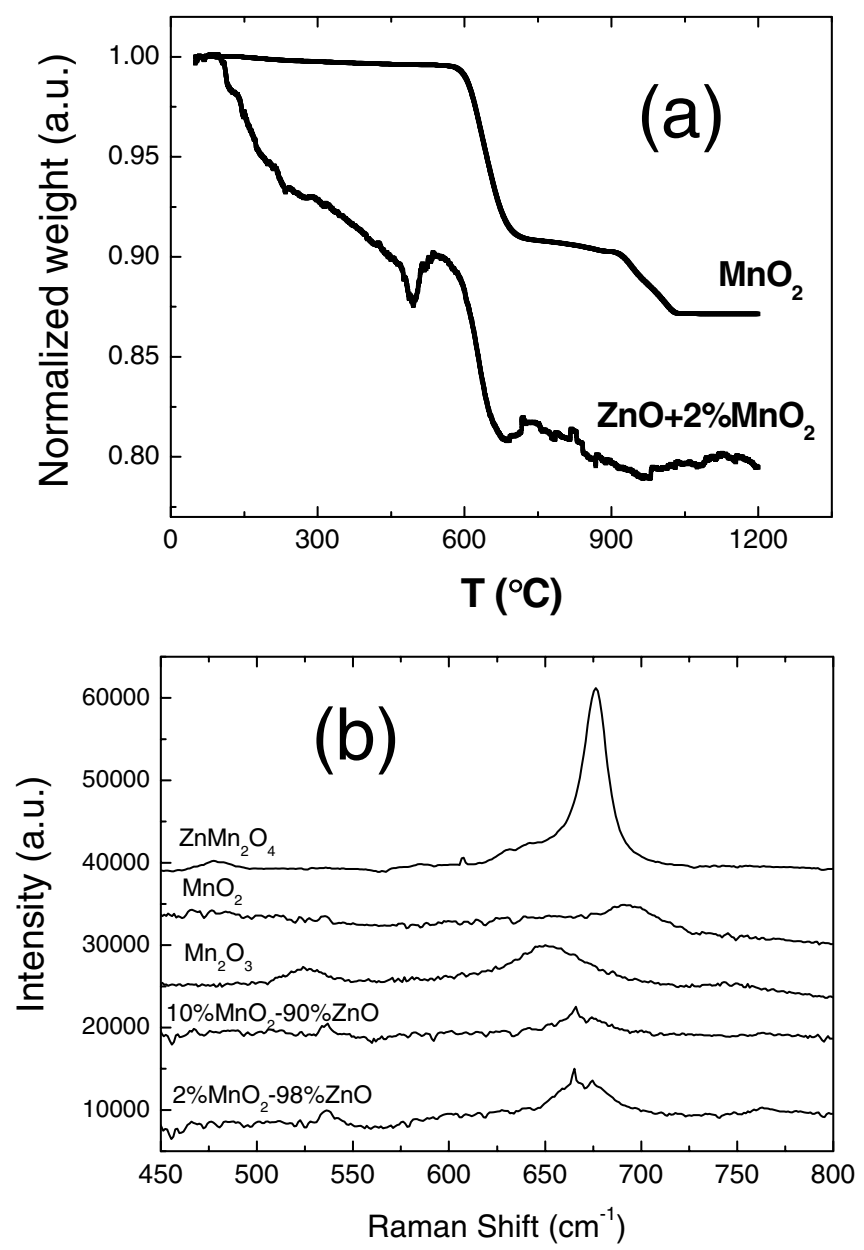

FIG. 3. (a) TGA from pure $\mathrm{MnO}_{2}$ and the component of $\mathrm{MnO}_{2}$ in $2 \% \mathrm{MnO}_{2}-98 \% \mathrm{ZnO}$. The latter was obtained by subtracting the data for pure $\mathrm{ZnO}$ from the experimental results. (b) Raman spectra from $2 \% \mathrm{MnO}_{2}-98 \% \mathrm{ZnO}, 10 \% \mathrm{MnO}_{2}-90 \% \mathrm{ZnO}, \mathrm{MnO}_{2}$, $\mathrm{Mn}_{2} \mathrm{O}_{3}$, and $\mathrm{ZnMn}_{2} \mathrm{O}_{4}$.

modified by the presence of $\mathrm{Zn}$. In this sense, TGA [Fig. 3(a) and also Fig. 2(b) of Ref. [3]] shows that the $\mathrm{MnO}_{2} \rightarrow \mathrm{Mn}_{2} \mathrm{O}_{3}$ reduction process $\left(\mathrm{Mn}^{4+} \rightarrow \mathrm{Mn}^{3+}\right)$ is very sharp and takes place between $500{ }^{\circ} \mathrm{C}$ and $600{ }^{\circ} \mathrm{C}$. However, in the presence of $\mathrm{Zn}, \mathrm{Mn}^{4+} \rightarrow \mathrm{Mn}^{3+}$ reduction starts at lower temperature (about $200{ }^{\circ} \mathrm{C}$ ) and there is a progressive reduction up to $600^{\circ} \mathrm{C}$. Therefore, the temperature range where $\mathrm{Mn}^{3+}$ and $\mathrm{Mn}^{4+}$ coexist is wider in the presence of $\mathrm{Zn}$.

In order to get more reliable information of manganese oxidation states, Raman studies were performed. Raman spectra of $2 \% \mathrm{MnO}_{2}-98 \% \mathrm{ZnO}$ and $10 \% \mathrm{MnO}_{2}-90 \% \mathrm{ZnO}$ samples annealed at $500{ }^{\circ} \mathrm{C}$ as well as those corresponding to references are displayed in Fig. 3(b). Raman modes from $\mathrm{MnO}_{2}$ and $\mathrm{Mn}_{2} \mathrm{O}_{3}$ in the $600-700 \mathrm{~cm}^{-1}$ region appear at 645 and $690 \mathrm{~cm}^{-1}$, respectively. The ferromagnetic samples show two overlapping peaks in this region at 674 and $659 \mathrm{~cm}^{-1}$. The former is characteristic of the spinel phase; the latter is related to an intermediate oxidation state [8], that is, local coexistence of $\mathrm{Mn}^{+4}$ and $\mathrm{Mn}^{+3}$. In our case, the presence of $\mathrm{Zn}$ seems to stabilize this mixture of oxidation states.

It is worth noting that the RT FM is found only for the latter samples annealed in the temperature range where $\mathrm{Mn}^{3+}$ and $\mathrm{Mn}^{4+}$ coexist, pointing to the simultaneous presence of both oxidation states as responsible for the observed RT FM. The coexistence of $\mathrm{Mn}^{3+}$ and $\mathrm{Mn}^{4+}$ is known to be responsible for FM via the double-exchange mechanism in different compounds $[9,10]$, which usually exhibits a large Curie temperature $\left(T_{\mathrm{C}}\right)$ even above RT [11]. Actually, the situation is similar to that found in $\mathrm{La}_{1-x} \mathrm{Ca}_{x} \mathrm{MnO}_{3}$. For $x=1$ the valence of $\mathrm{Mn}$ is $4+$, whereas for $x=0$ the valence is $3+$. None of those compounds is FM, but the intermediate values of $x$, which yield to a mixture of $\mathrm{Mn}^{3+}$ and $\mathrm{Mn}^{4+}$, give rise to the appearance of FM with high $T_{\mathrm{C}}$.

It has not been described yet how the presence of $\mathrm{Zn}$ modifies the kinetics of $\mathrm{MnO}_{2}$ reduction. During the annealing process, $\mathrm{Zn}$ diffuses into $\mathrm{MnO}_{2}$ grains favoring the reduction to $\mathrm{Mn}_{2} \mathrm{O}_{3}$ and subsequent formation of the $\mathrm{Zn}_{x} \mathrm{Mn}_{3-x} \mathrm{O}_{4}$. This is clearly observed by EDS microanalysis, since different areas of the same particle show changes in the $\mathrm{Mn} / \mathrm{Zn}$ ratio. The $\mathrm{Mn}^{3+}$ oxidation state seems to be associated with phases containing $\mathrm{Zn}$ that are doped $\mathrm{Mn}_{2} \mathrm{O}_{3}$ and $\mathrm{Zn}_{x} \mathrm{Mn}_{3-x} \mathrm{O}_{4}$, whereas $\mathrm{Mn}^{4+}$ is in $\mathrm{MnO}_{2}$. Therefore, it is expected that both $\mathrm{Mn}^{3+}$ and $\mathrm{Mn}^{4+}$ coexist in the interface which separates regions with $\mathrm{Zn}$ from those without $\mathrm{Zn}$, that is, the $\mathrm{Zn}$ diffusion front into Mn oxide grains. Figure 4 summarizes this situation. This would explain the low saturation magnetization value reported $[1,3,6]$ in the RT ferromagnetic bulk systems, and that the ferromagnetic phase is observed over a large paramagnetic component but it has not been reported as isolated: FM is not associated with a phase but with the interface between nonferromagnetic phases.

In order to confirm this point, we have tried to increase the $\mathrm{MnO}_{2} / \mathrm{ZnO}$ interface (and therefore the surface of the $\mathrm{Zn}$ diffusion front) by growing a thin film multilayer sample consisting of 40 sequential $\mathrm{ZnO} / \mathrm{MnO}_{2}$ bilayers by pulsed laser deposition onto a Si substrate. The $\mathrm{ZnO}$ and $\mathrm{MnO}_{2}$ individual layers are 7.5 and $1.5 \mathrm{~nm}$ thick, respectively. The hysteresis loops of this sample are shown in Fig. 4(b). The saturation magnetization is $1 \mathrm{emu} / \mathrm{cm}^{3}, 2$ orders of magnitude larger than the highest $\mathrm{M}_{\mathrm{s}}$ reported for this system in bulk, and similar to the best value reported for thin films [12], confirming that the FM is originated at the interface. The coercive force for this sample [around 50 Oe at $5 \mathrm{~K}$ as shown in the inset of Fig. 4(b)] is smaller than for bulk material (180 Oe at $5 \mathrm{~K}$ ) [6]. Thereby, further analysis of the anisotropy and technical magnetization processes in these multilayers must be carried out. Despite the small size of the magnetic entities, a noticeable contribution of superparamagnetic regions to the magnetization can 

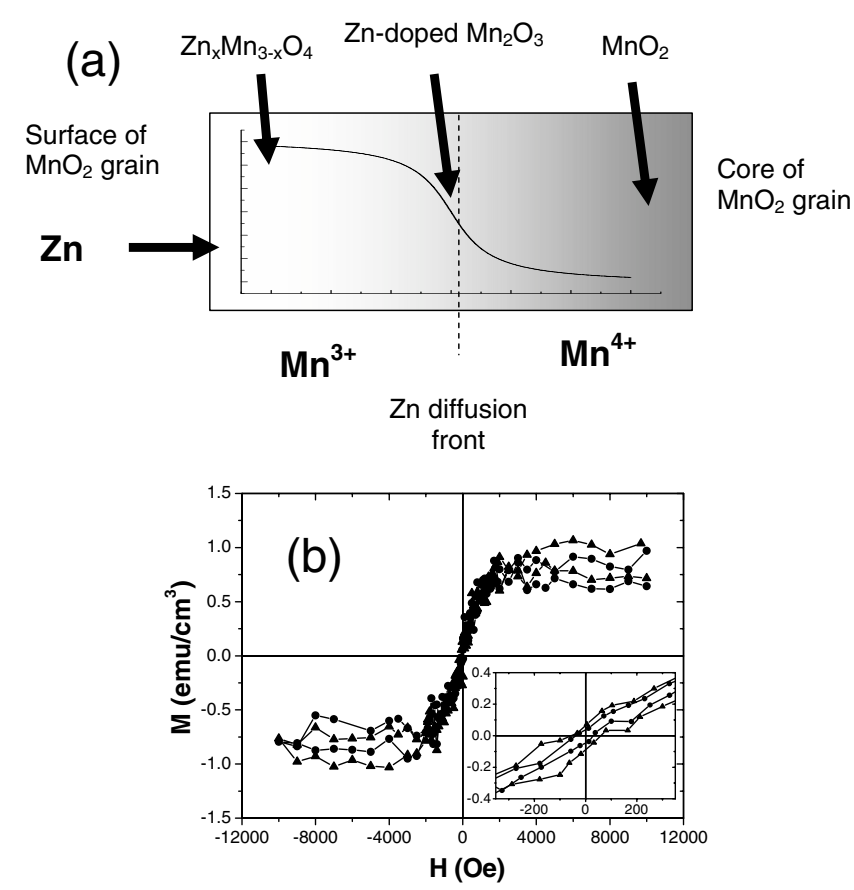

FIG. 4. (a) Scheme of the different phases at the Mn oxide grains after annealing at $500{ }^{\circ} \mathrm{C}$ and the oxidizing states of $\mathrm{Mn}$. The graph indicates the concentration profile of $\mathrm{Zn}$ inside the grain. (b) Hysteresis loops from a $40 \mathrm{MnO}_{2} / \mathrm{ZnO}$ multilayer prepared by laser ablation at $5 \mathrm{~K}$ (triangles) and $300 \mathrm{~K}$ (circles). Inset shows a detail of the loops at low $H$. The paramagneticdiamagnetic component has been subtracted to clearly show the FM phase.

be disregarded since, in that case, the hysteresis loops at 5 and $300 \mathrm{~K}$ shown in Fig. 4(b) should be fairly different (both curves should overlap when represented as a function of $H / T)$. The XRD patterns from this sample showed a clear signal from $\mathrm{Mn}_{2} \mathrm{O}_{3}$, confirming that this phase is involved in the interface that give rises to the ferromagnetic behavior. The composition of this interface could be similar to that proposed by Kundaliya et al. [3].
In summary, we showed that RT FM in the Mn- Zn-O system is due to the incorporation of $\mathrm{Zn}$ into the $\mathrm{MnO}_{2}$ grains. The presence of $\mathrm{Zn}$ modifies the kinetics of thermal reduction $\mathrm{Mn}^{4+} \rightarrow \mathrm{Mn}^{3+}$ during the annealing process, favoring the coexistence of both oxidation states, which gives rise to a double-exchange mechanism, responsible for the RT ferromagnetic behavior. Annealing above $500{ }^{\circ} \mathrm{C}$ increases $\mathrm{Zn}$ diffusion on manganese oxides, leading to spinel $\mathrm{Zn}_{x} \mathrm{Mn}_{3-x} \mathrm{O}_{4}$ phases. The FM arises at the interface or $\mathrm{Zn}$ diffusion front, and it can be increased by maximizing the interface preparing multilayers. This is a new class of surface magnetism: double-exchange mechanism, at the interface between two compounds containing Mn atoms in different oxidation states.

This work has been partially supported by the University Complutense Project No. PR1/05-13325. Partial support from the EU Network of Excellence SANDIE is also acknowledged.

*Corresponding author.

Electronic address: ahernando@renfe.es

[1] P. Sharma et al., Nat. Mater. 2, 673 (2003).

[2] T. Dietl, H. Ohno, F. Matsukura, J. Cibert, and D. Ferrand, Science 287, 1019 (2000).

[3] D. Kundaliya et al., Nat. Mater. 3, 709 (2004).

[4] G. Lawes, A. S. Risbud, A. P. Ramírez, and R. Seshadri, Phys. Rev. B 71, 045201 (2005).

[5] C. N. R. Rao and F. L. Deepak, J. Mater. Chem. 15, 573 (2005).

[6] J. L. Costa-Krämer et al., Nanotechnology 16, 214 (2005).

[7] S. Asbrink et al., Phys. Rev. B 60, 12651 (1999).

[8] C. B. Azzoni, Solid State Commun. 112, 375 (1999).

[9] M. B. Salamon and M. Jaime, Rev. Mod. Phys. 73, 583 (2001).

[10] J. Alonso et al., Phys. Rev. B 64, 172410 (2001).

[11] T. Okuda et al., Phys. Rev. Lett. 81, 3203 (1998).

[12] N. Theodoropoulou et al., cond-mat/0408294. 